\title{
Comparison of Single-Walled and Multiwalled Carbon Nanotubes Durability as Pt Support in Gas Diffusion Electrodes
}

\author{
Mehdi Asgari and Elaheh Lohrasbi \\ NFCS, NSTRI, Tehran, P.O. Box 11365-8486, Iran \\ Correspondence should be addressed to Mehdi Asgari; mehdiasgari2002@yahoo.com
}

Received 31 October 2012; Accepted 21 November 2012

Academic Editors: S. Park, W. Xing, and S. Yoon

Copyright (C) 2013 M. Asgari and E. Lohrasbi. This is an open access article distributed under the Creative Commons Attribution License, which permits unrestricted use, distribution, and reproduction in any medium, provided the original work is properly cited.

\begin{abstract}
Durability of single-walled (SWCNT) and multiwalled carbon nanotubes (MWCNT) as Pt supports was studied using two accelerated durability tests (ADTs), potential cycling and potentiostatic treatment. ADT of gas diffusion electrodes (GDEs) was once studied during the potential cycling. Pt surface area loss with increasing the potential cycling numbers for GDE using SWCNT was shown to be higher than that for GDE using MWCNT. In addition, equilibrium concentrations of dissolved Pt species from GDEs in $1.0 \mathrm{M} \mathrm{H}_{2} \mathrm{SO}_{4}$ were found to be increased with increasing the potential cycling numbers. Both findings suggest that Pt detachment from support surface plays an important role in Pt surface loss in proton exchange membrane fuel cell electrodes. ADT of GDEs was also studied following the potentiostatic treatments up to $24 \mathrm{~h}$ under the following conditions: argon purged, $1.0 \mathrm{M} \mathrm{H}_{2} \mathrm{SO}_{4}, 60^{\circ} \mathrm{C}$, and a constant potential of $0.9 \mathrm{~V}$. The subsequent electrochemical characterization suggests that GDE that uses MWCNT/Pt is electrochemically more stable than other GDE using SWCNT/Pt. As a result of high corrosion resistance, GDE that uses MWCNT/Pt shows lower loss of Pt surface area and oxygen reduction reaction activity when used as fuel cell catalyst. The results also showed that potential cycling accelerates the rate of surface area loss.
\end{abstract}

\section{Introduction}

The durability of proton exchange membrane fuel cell (PEMFC) is a major barrier to the commercialization of these systems for stationary and transportation power applications. Gas diffusion electrodes (GDEs) of PEMFCs use electrocatalysts for the oxidation of hydrogen at the anode and reduction of oxygen in air at the cathode. Currently, Pt supported on high surface area carbons is the best feasible electrocatalyst for PEMFC systems [1]. Limiting the commercialization of PEMFCs, electrocatalyst durability is a factor for consideration [2-4]. The degradation mechanisms proposed include catalyst dissolution [5, 6] and carbon support corrosion [7]. Carbon supports corrosion in acidic electrolytes involves the general steps of oxidation of carbon in the lattice structure (Reaction (1)) followed by hydrolysis (Reaction (2)) and finally gasification of the oxidized carbon to $\mathrm{CO}_{2}$ (Reaction (3)), wherein the subscript " $s$ " denotes surface species $[8,9]$ :

$$
\begin{gathered}
\mathrm{C}_{\mathrm{s}} \longrightarrow \mathrm{C}_{\mathrm{s}}^{+}+\mathrm{e}^{-} \\
\mathrm{C}_{\mathrm{s}}^{+}+\frac{1}{2} \mathrm{H}_{2} \mathrm{O} \longrightarrow \mathrm{C}_{\mathrm{s}} \mathrm{O}+\mathrm{H}^{+} \\
\mathrm{C}_{\mathrm{s}} \mathrm{O}+\mathrm{H}_{2} \mathrm{O} \longrightarrow \mathrm{CO}_{2}(\mathrm{~g})+2 \mathrm{H}^{+}+2 \mathrm{e}^{-}
\end{gathered}
$$

One strategy to decrease carbon support corrosion is to use carbon with high extent of graphitization, which is due to decreased defect sites on the carbon structure, where carbon oxidation starts $[10,11]$. With the development of novel carbon nanostructure materials [12], for example, carbon nanotubes (CNTs) [13, 14], carbon nanofibers [15], and so forth more and more attention is paid to their application as catalyst support [16-18]. It has been reported by several research groups that CNTs are more resistant to electrochemical oxidation than carbon black in both cases with and without Pt on them $[6,7,10,19]$. CNTs are usually considered as the rolled graphene sheets with a coaxis and with less dangling bonds and defects than carbon black 
$[10,19]$. CNTs can be divided essentially into two categories: SWCNTs and MWCNTs.

Recently, CNTs have been proposed as a promising support material for fuel cell catalysts $[18,20]$. Wang et al. [21] compared the electrochemical surface oxidation of carbon black Vulcan XC-72 and MWCNT. The subsequent electrochemical characterization at different treatment time intervals suggested that MWCNT is electrochemically more stable than Vulcan XC-72 with less surface oxide formation and $30 \%$ lower corrosion current under the investigated condition. As a result of high corrosion resistance, MWCNT shows lower loss of Pt surface area and oxygen reduction reaction activity when used as fuel cell catalyst support [21].

The studies of Shao et al. showed that MWCNTs are more resistant to electrochemical oxidation than carbon black under aqueous sulfuric acid solution. As a result of high corrosion resistance, MWCNTs show lower loss of Pt surface area and catalytic activity (than carbon black) when used as fuel cell catalyst support [10]. Wang et al. found that the use of MWCNTs with high degree of graphitization as a support also improves the durability of the resultant catalyst [22]. Recent efforts have showed that, compared to commercial carbon black/Pt catalyst, SWCNT/Pt catalyst in hydrogen fuel cells shows improved performance at higher anodic pressures [23].

CNTs clearly have a wide variety of applications, and wide ranging properties and structures that we are still in the process of discovering. This study focuses on comparing the durability of GDEs using SWCNTs and MWCNTs as support for catalysts, but durability study in PEMFC has remained a difficult topic because of the lengthy duration of the test time required (i.e., several thousand hours or more), so in this study, an accelerated durability test (ADT) is used $[24,25]$.

The electrochemically active Pt sites in the membrane electrode assembly (MEA) are the most effective ones for fuel cell electrode reactions. So, the more sites of electrochemically active $\mathrm{Pt}$ are (e.g., electrochemical active surface area, EAS), the higher the performance of the fuel cell electrodes is.

\section{Experimental}

2.1. Materials and Apparatus. Sodium borohydride, $\mathrm{H}_{2} \mathrm{PtCl}_{6}$, sulfuric acid, single-walled carbon nanotube and multiwalled carbon nanotube were analytically graded and purchased from Aldrich and Alfa Acer companies. Carbon Vulcan XC-72R and polytetrafluoroethylene (PTFE) were purchased from ElectroChem, Inc., and carbon paper TGP-H-0120 was from Toray.

All electrochemical experiments were carried out using an Ivium Compactstate Electrochemical Analyzer equipped with a personal computer for data storage and processing. All measurements were taken at $25 \pm 1^{\circ} \mathrm{C}$, maintained with a water thermostatic bath.

ICP analysis with an IRIS advantage ICP atomic emission spectroscopy (ICP-AES) system (Varian Austria) was conducted to determine the dissolved metal concentration in solution.

2.2. Surface Modification of SWCNTs and MWCNTs. The surface of commercial CNTs was functionalized with carboxyl functional groups. For this purpose, commercial CNTs and concentrated nitric acid were refluxed at $140^{\circ} \mathrm{C}$ for $10 \mathrm{~h}$. When the mixture was cooled down, centrifuged ( $15 \mathrm{~min}$ at $5000 \mathrm{rpm}$ ), the precipitates were washed with deionized water until the $\mathrm{pH}$ of waste water is around 7 . Then the CNTs were decanted and dried in vacuum oven at $60^{\circ} \mathrm{C}$ over a night.

2.3. Electrocatalyst Preparation. To support Pt nanoparticles on the CNTs, the well-known impregnation method was adopted and followed by liquid-phase borohydride. A mixture of the modified CNTs and $\mathrm{H}_{2} \mathrm{PtCl}_{6}$ was suspended by sonication in $40 \mathrm{~mL}$ of deionized water. Subsequently, this $\mathrm{Pt}$ precursor was reduced on the surface of CNTs simultaneously by $\mathrm{NaBH}_{4}$ as the reducing agent and washed with deionized water several times. The filtrate was collected to determine an exact load by measuring the Pt residue. After drying, the Pt nanoparticles that supported CNTs were obtained.

2.4. Fabrication of GDEs and Electrochemical Measurements. Porous GDEs were constructed according to a previously described procedure [26]. To prepare the polytetrafluoroethylene (PTFE), bonded porous gas diffusion layer (GDL), a commercially available carbon Vulcan XC-72R 70\% and $30 \%$ PTFE emulsions were used and painted onto carbon paper TGP-H-0120. The resulting composite structure was dried in air at $80-90^{\circ} \mathrm{C}$ for $1 \mathrm{~h}$, followed by thermal treatment at $250^{\circ} \mathrm{C}$ for $30 \mathrm{~min}$ to remove the dispersion agent contained in the PTFE and finally sintered in air at $340^{\circ} \mathrm{C}$ for $15 \mathrm{~min}$. The PTFE is effective as a binder and impacts hydrophobicity to the gas diffusion regime of the electrode.

To prepare the catalyst layer, a mixture comprised of a homogeneous suspension of Nafion, one of the prepared catalysts, and isopropyl alcohol as solvent was homogenized using a sonicator (Misonix Model S-3000) for $20 \mathrm{~min}$. The prepared ink was painted on GDL. The resulting composite structure was dried in air at $25^{\circ} \mathrm{C}$ for $1 \mathrm{hr}$ and finally sintered in air at $140^{\circ} \mathrm{C}$ for $45 \mathrm{~min}$. Nafion and Pt loadings were 1 and $0.5 \mathrm{mg} / \mathrm{cm}^{2}$ in the GDEs, respectively. For preparing GDE1 and GDE2, the Pt-supported SWCNTs and Pt-supported MWCNTs were used, respectively.

2.5. Electrochemical Studies. The reduction of oxygen was investigated with the porous GDEs (geometric exposed area of $1.3 \mathrm{~cm}^{2}$ ) in $1 \mathrm{M} \mathrm{H}_{2} \mathrm{SO}_{4}$ solution. Durability investigation of the GDEs was carried out by the ADT cell. The ADT cell consists of a three-electrode system, which includes a reference electrode (an $\mathrm{Ag} / \mathrm{AgCl}$ reference electrode was placed close to the working electrode surface), a Pt mesh counter electrode, and a GDE as a working electrode. The GDEs were mounted in a Teflon holder containing a high pyrolytic graphite disk as a current collector (which had an arrangement for the oxygen feed from the back of the electrode). 


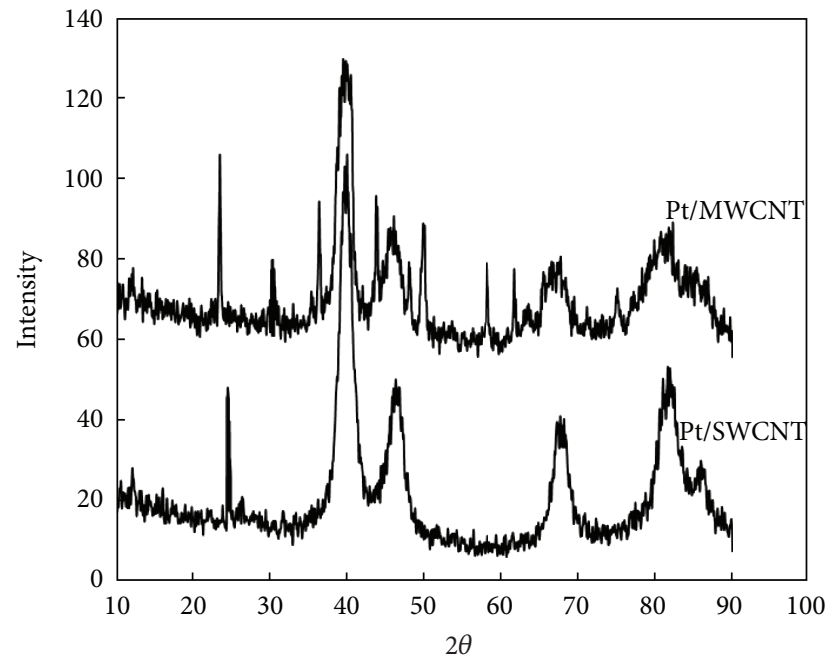

Figure 1: X-ray diffraction patterns of Pt/MWCNT and SWCNT/ Pt.

\section{Results and Discussion}

3.1. Characterization of GDEs. Figure 1 shows the X-ray diffraction patterns of the CNT-supported Pt catalyst. The first peak located at ca. $26.5^{\circ}$ in the XRD patterns is associated with the CNT support. The other four peaks are characteristic of the face-centered-cubic (fcc) crystalline Pt (JCPDS-ICDD, Card no. 04-802), corresponding to the planes (1 111$),\left(\begin{array}{lll}2 & 0 & 0\end{array}\right)$, (2 20 ), and (3 11 ) at $2 \theta$ values of ca. $39.6^{\circ}, 46.1^{\circ}, 67.2^{\circ}$, and $81.8^{\circ}$, respectively, indicating that catalysts have principally single phase disordered structures.

Figure 2 shows the TEM images of the nanocrystalline PtCNT composite material prepared at the surface of a GDE. First of all, it can be seen that the CNTs are cross-linked with each other to form a highly porous architecture, suitable for the immobilization of Pt nanoparticles. Subsequently, the Pt nanoparticles have grown by chemical reduction into the CNT matrix under a homogeneous distribution. It is seen that the Pt nanoparticles are distributed on the CNTs surface in the form of single stick. Moreover, the TEM image clarifies that the aggregation of $\mathrm{Pt}$ nanoparticles is unobvious, and the nanoparticles are highly dispersed on the MWCNTs.

3.2. Durability Investigation of GDEs. Durability investigation of the GDE1 with Pt/SWCNT and GDE2 with Pt/MWCNT as electrocatalyst was carried out by the ADT cell. In the ADT cell, the liquid electrolyte has easier access to the inside of the catalyst layer than the solid one, for example, Nafion membrane in a proton exchange membrane fuel cell. So in the case of the ADT, the entire active surface area of the electrode is exposed to the electrolyte and is active, while in a real PEMFC, the catalyst is only active in contact with the Nafion membrane. Thus the degradation of GDEs in the case of the ADT is accelerated.

3.3. Cyclic Voltammetric Study of GDEs. Figure 3 shows the CVs for GDE1 with Pt supported SWCNT (SWCNT/Pt)
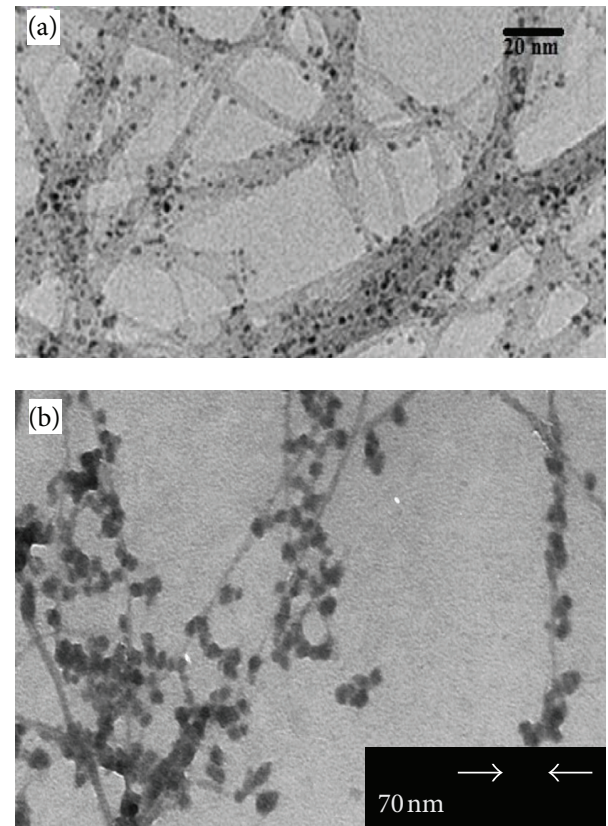

Figure 2: TEM photo of (a) Pt/MWCNT and (b) SWCNT/Pt.

as cathode catalyst and GDE2 with MWCNT supported Pt (MWCNT/Pt) as cathode catalyst after consecutive cycling test.

Hydrogen adsorption and desorption (HAD) peak appeared in the -0.2 to $0.2 \mathrm{~V}$ potential range. There is an increase in the HAD peak and then a decrease of it after further cycles.

During potential cycling, up to 50th cycle, oxygen atoms are being generated by the catalyst particles. Several types of surface oxides were generated on $\mathrm{CNTs}$, including $>\mathrm{COH}$, $>\mathrm{CO}$, and $>\mathrm{COO}-$ groups, because of low $\mathrm{pH}(<1)$ and high oxidative potential [27]. Our findings show an increase in HAD peaks with the presence of functional groups due to much easier proton access to the catalyst and leading to a larger active surface area [28]. So, an increase in the HAD peak occurred up to 50th cycle.

After the 50th cycle, the decrease in HAD area with increasing number of cycling was clearly observed for both GDEs because $\mathrm{CO}_{2}$ or $\mathrm{CO}$ formed during the carbon oxidation, leaves the GDEs, forces Pt nanoparticles to fall off the carbon support or agglomerate, and decreases the electrochemical surface area, as shown in Figure 4 schematically $[7,10]$.

For determining the EAS, the charge caused by adsorbed hydrogen $\left(\mathrm{Q}_{\mathrm{H}}\right)$ was obtained by integration of the corresponding peak in the voltammogram with a double layer charging current as a base line:

$$
\mathrm{EAS}=\frac{\mathrm{Q}_{\mathrm{H}}}{[\mathrm{Pt} \times 0.21]},
$$

where $[\mathrm{Pt}]$ represents the Pt loading $\left(\mathrm{mg} \mathrm{cm}^{-2}\right)$ in the electrode, $\mathrm{Q}_{\mathrm{H}}$ is the charge for hydrogen desorption $(\mathrm{mC})$, and 0.210 represents the charge required to oxidize a monolayer of $\mathrm{H}_{2}$ on bright $\mathrm{Pt}[26,29]$. 


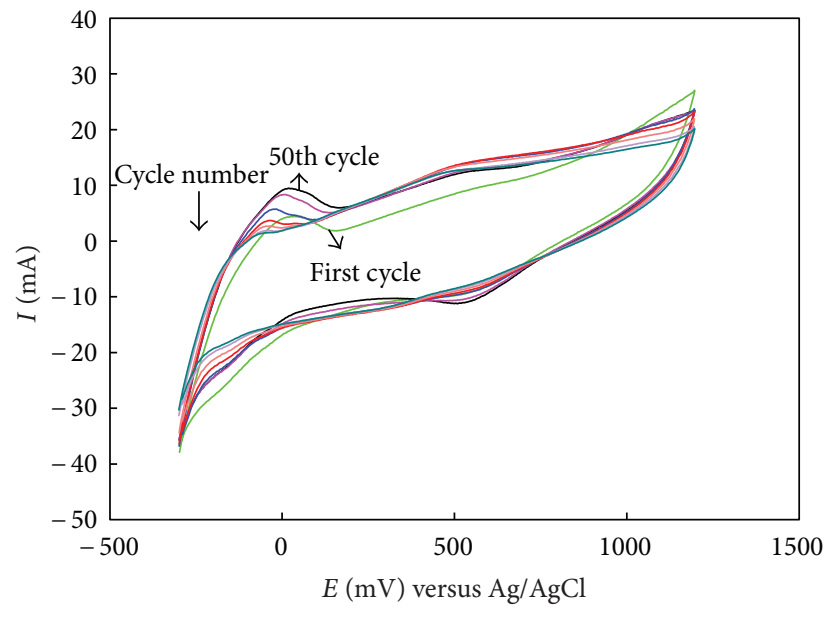

(a)

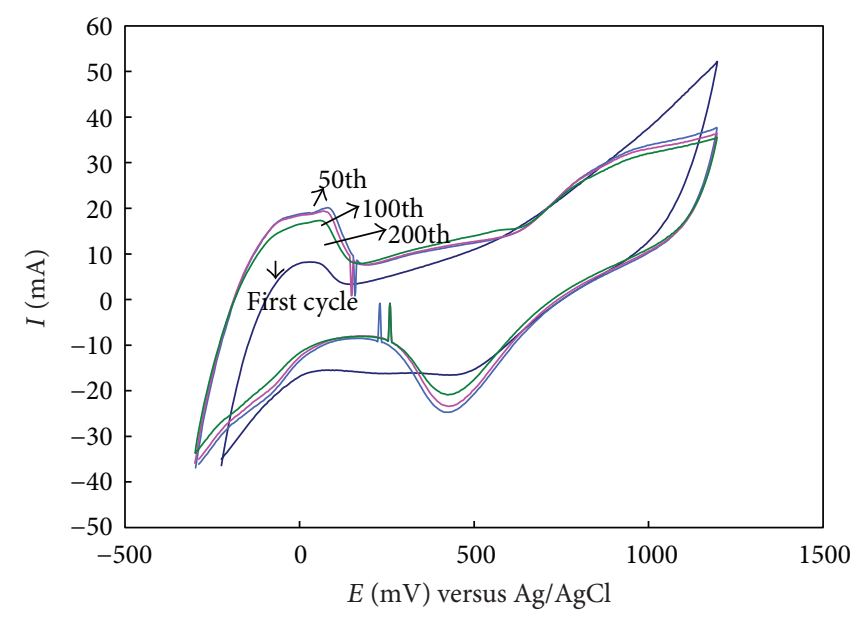

(b)

Figure 3: Cyclic voltammogram of (a) GDE1 and (b) GDE2 after 1, 50, 60, 80, 150, 300, 500, and 600 cycles, scan rate $50 \mathrm{mV} \cdot \mathrm{s}^{-1}$.

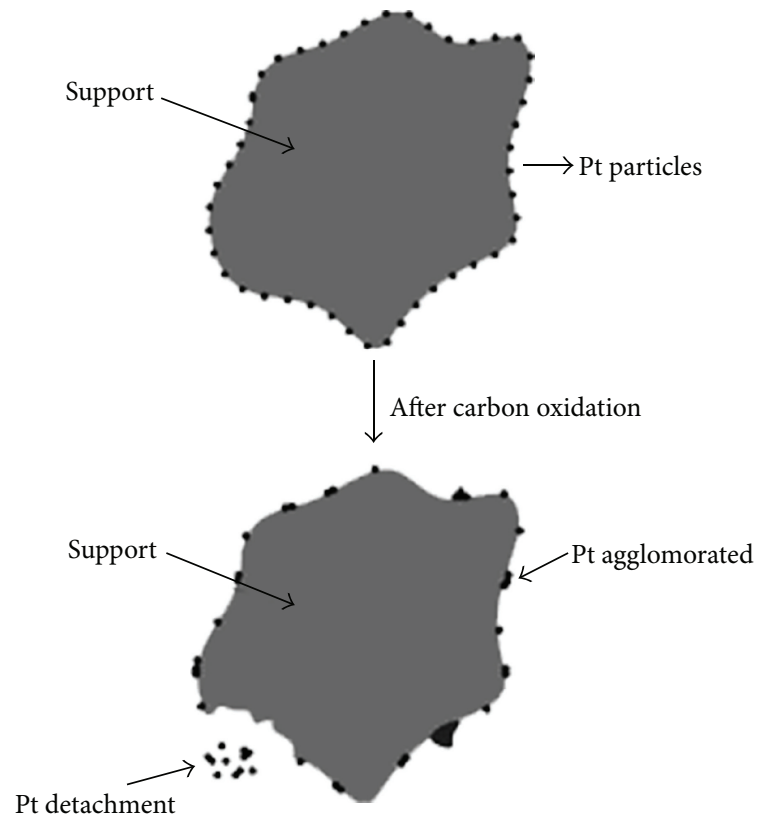

FIGURE 4: Schematic of Pt agglomeration on and Pt detachment from the surface of support material.

A larger EAS implies a better electrode, as more catalyst sites are available for the electrode reactions. As shown in Figure 5, the EAS of GDE2 during potential cycling is much higher than that of GDE1. After the 600th cycle, the EAS decreases from 205 to $59 \mathrm{~cm}^{2} \mathrm{mg}^{-1}$ Pt for GDE1 (by 71\%), and from 1029 to $495 \mathrm{~cm}^{2} \mathrm{mg}^{-1} \mathrm{Pt}$ for GDE2 (by 52\%). It is worth noting that, in the ADT method, the electrolyte has easier access to the inside of the catalyst layer than the solid one in a PEMFC. Thus the degradation of GDEs in the case of the ADT is accelerated.

According to results, the degradation rate of GDE2 is slower than GDE1. The decrease in EAS mainly results

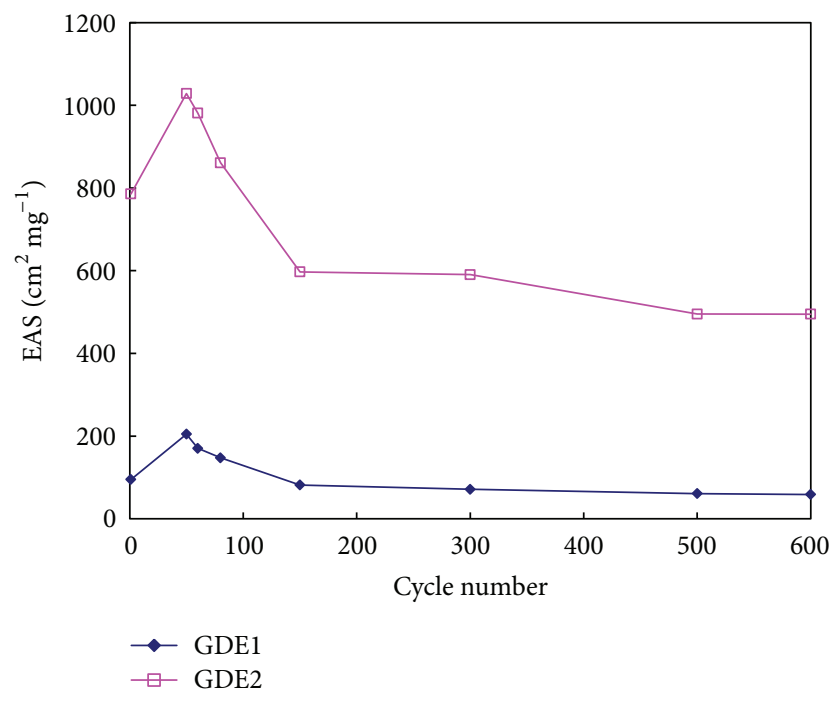

Figure 5: The amount of EAS as a function of cycling number as determined from CVs shown in Figure 1.

from the increase of Pt nanoparticle size (agglomeration of Pt nanoparticles) or the detachment (dissolution) of $\mathrm{Pt}$ nanoparticles from the carbon support [30]. To determine what really caused the EAS loss and to investigate how pt detaches during potential cycling, the $\mathrm{H}_{2} \mathrm{SO}_{4}$ electrolyte was periodically taken out from the liquid cell for $\mathrm{Pt}^{2+}$ concentration analysis (using ICP method) after each 600 cycle. Figure 6 presents the $\mathrm{Pt}^{2+}$ concentration as a function of cycling number.

Darling and Meyers [31] have recently developed an initial numerical model for the Pt area loss induced by voltage cycling, which includes a potential-dependent dissolution of $\mathrm{Pt}\left(\mathrm{Pt} \rightarrow \mathrm{Pt}^{2+}+2 \mathrm{e}\right)$, chemical dissolution of $\mathrm{Pt}$ oxide $(\mathrm{PtO}+$ $2 \mathrm{H}^{+} \rightarrow \mathrm{Pt}^{2+}+\mathrm{H}_{2} \mathrm{O}$ ) and surface tension driven growth of the Pt nanoparticles. The results of ICP analysis indicated that 


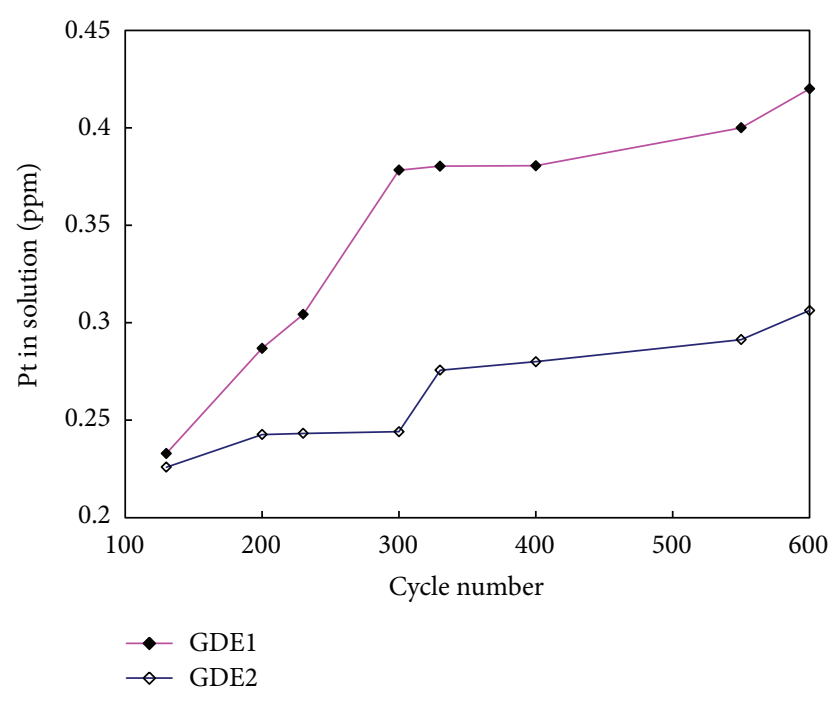

FIGURE 6: Comparison of Pt concentration (ppm) during the cycling in $1 \mathrm{M} \mathrm{H}_{2} \mathrm{SO}_{4}$ for GDE1 and GDE2.

the amount and the rate of $\mathrm{Pt}$ dissolution were much higher for GDE1 than GDE2. These results suggest that EAS loss of GDE1 during 600 cycles might be related to a significant amount of Pt dissolution into the electrolyte. The results also suggest that Pt agglomeration on MWCNT support in GDE2 might lead to EAS loss of GDE2 and Pt detachment from the support occurred slower in GDE2 than in GDE1. This is due to the specific interaction between Pt nanoparticles and MWCNT support.

The $\pi$-electrons play an important role in the electronic structures and the interaction between CNT supports and Pt nanoparticles. Pt nanoparticles bond with support through the interaction between $\mathrm{Pt}$ and $\pi$ electrons of the graphene sheets in support; the stronger the $\pi$ bonds were ( $\mathrm{sp}^{2}$-hybridized carbon), the stronger the interaction is [7,31]. Elim et al. [32], by using the absorption spectrum of the MWCNT film at the photon energies between 1 and $6 \mathrm{eV}$, showed that the optical property of the MWCNT film is dominated by an absorption resonance peaked at $5.4 \mathrm{eV}$. It was assigned as the $\pi$-plasmon resonance, which is about $0.4 \mathrm{eV}$ blue shifted in comparison to that of SWCNTs measured by Lauret et al. [33]. The blue shift is anticipated since there is more $\pi$ electrons in MWCNTs than in SWCNTs. So there are more $\pi$-electrons in MWCNTs that cause stronger interactions between $\mathrm{Pt}$ and MWCNTs. Therefore, Pt detachment from support occurred slower in GDE2 than in GDE1.

As Figure 3 shows there is also a small current peak appearing in the range of $0.4-0.5 \mathrm{~V}$ in both support electrodes, which results from the surface oxide formation which is due to the hydroquinone-quinine (HQ-Q) redox couple on the CNT support surface $[34,35]$. The reaction corresponding to the current peaks in the HQ-Q redox region can be formulated as follows [21]:

$$
\mathrm{C}=\mathrm{O}+\mathrm{e}^{-}+\mathrm{H}^{+} \longleftrightarrow \mathrm{C}-\mathrm{OH}
$$

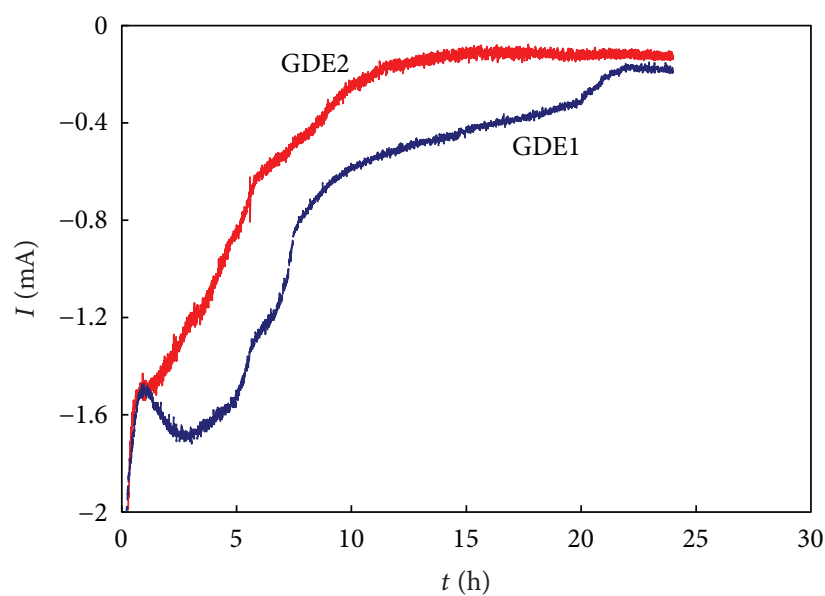

FIGURE 7: Polarization data as a function of time for the potentials fixed at $0.9 \mathrm{~V}$ for GDE1 and GDE2.

As shown in Figure 3(b), the peak in the HQ-Q redox region becomes stronger with increasing the potential cycling number. It is also accompanied by a general increase in the capacitive current. The increased peak current and capacitive current suggest a higher degree of surface carbon oxidation with the potential cycling. As shown in Figure 3, increasing of the peak current through potential cycling is less in GDE1 that uses SWCNT as support (Figure 3(a)). This fact suggests that surface carbon (SWCNT) oxidation in GDE1 is less than in the surface carbon (MWCNT) oxidation in GDE2, but as shown in the last results Pt bonds are weaker with SWCNT and can detach faster from it. So finally Pt/MWCNT is more stable than Pt/SWCNT during the potential cycling. These findings suggest that catalyst detachment in the GDEs is a major contributor to the catalyst degradation. Similar results have been reported by Wang et al. [21] who compared electrochemical surface oxidation of carbon black Vulcan XC-72 and MWCNT through potentiostatic treatments. Their results showed that MWCNT is electrochemically more stable than carbon black Vulcan XC-72.

A peak is also observed in Figure 3 in the potential domain of $0.7-1.2 \mathrm{~V}$, corresponding to the formation of Ptoxide species. This peak is barely visible in GDE1 (Figure 3(a)). A single peak during the cathodic sweep was also observed. This peak is normally assigned to the oxide reduction profile of the metals.

3.4. Chronoamperometric Study of GDEs. The observed change in the oxygen reduction current as a function of time at constant potential of $0.9 \mathrm{~V}$ is presented in Figure 7. As the results indicated, the oxygen reduction current decreases as the ADT proceeds. At the beginning of the experiment, the current initially increases until it reaches a maximum value. This initial increase is believed to occur as part of the initial wetting and saturation of the thin Nafion layer covering the catalyst particles. Once the current reaches the maximum, it starts to decrease. The chronoamperometric curves of GDEs (Figure 7) showed that under the same conditions GDE2 shows less corrosion current than GDE1. 


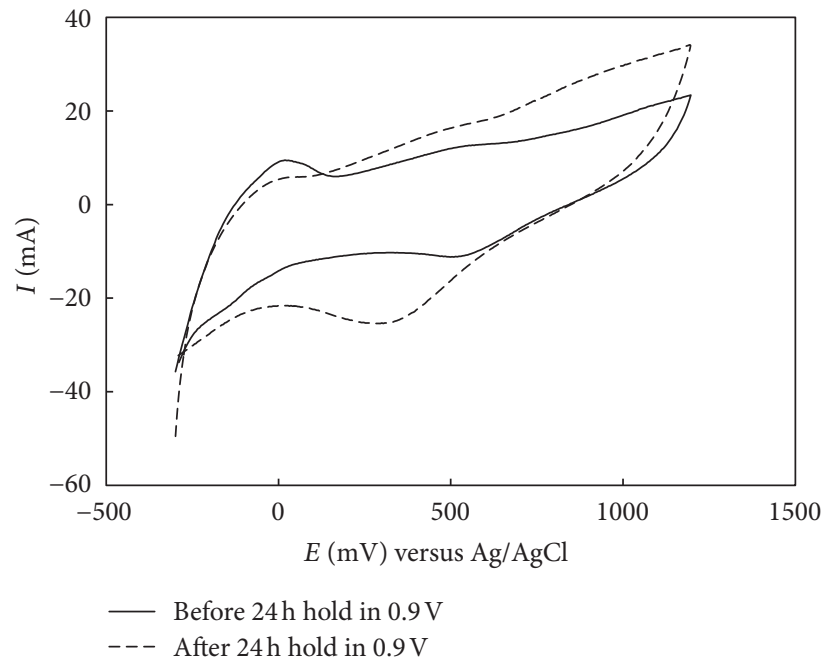

(a)

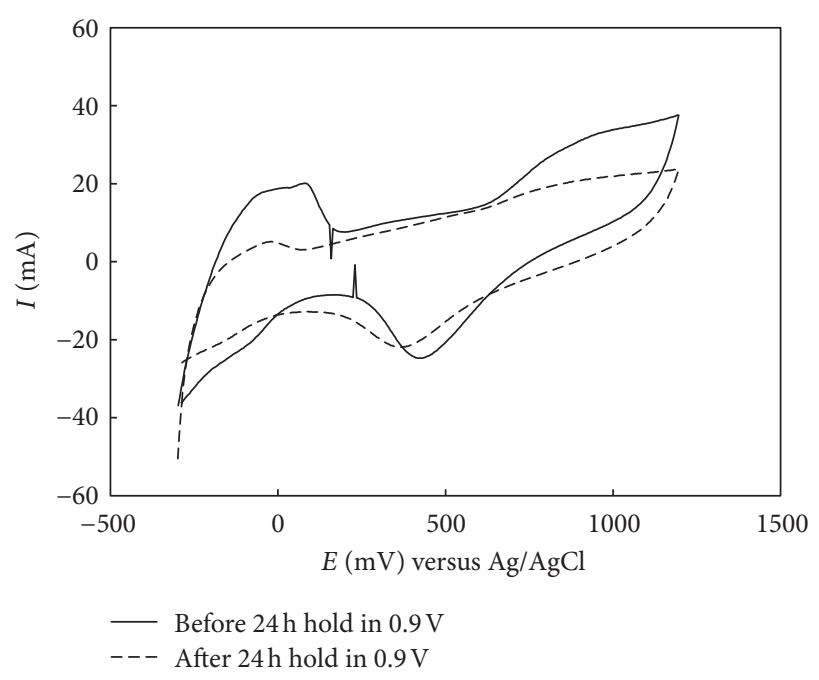

(b)

FIGURE 8: Cyclic voltammograms of (a) GDE1 and (b) GDE2 before and after $24 \mathrm{~h}$ hold tests in constant potential $0.9 \mathrm{~V}$.

To estimate the effect of the applied potential on the oxygen reduction current, the following equation was used:

$$
\mathrm{ORR}_{\text {decrease }} \%=\left[\frac{\left(I_{\max }-I_{\mathrm{s}}\right)}{I_{\max }}\right] \times 100
$$

where $I_{\mathrm{s}}$ is the steady state current and $I_{\max }$ is the maximum oxygen reduction current measured. The results presented in Figure 7 indicate that oxygen reduction reaction (ORR) is decreased by $78 \%$ in GDE1 and 75\% in GDE2.

The stability of both GDEs has also been investigated by CV curves after $0.9 \mathrm{~V}$ potentiostatic hold test. The CV curves of GDEs after $0.9 \mathrm{~V}$ potentiostatic $24 \mathrm{~h}$ hold test are presented in Figure 8, where EAS decreases as the ADT proceeds in both GDEs. Even after being held for $24 \mathrm{~h}$ at $0.9 \mathrm{~V}$ potentiostatic test, GDE2 showed higher EAS and thus better performance than GDE1. After holding the potential for $24 \mathrm{~h}$ at $0.9 \mathrm{~V}$, the EAS decreased by $55 \%$ and $25 \%$ in GDE1 and GDE2, respectively. It shows that the durability and stability of GDE2 are higher than those of GDE1.

These results also indicate that potential cycling leads to accelerated EAS losses compared to the extended holds at a constant potential $(0.9 \mathrm{~V})$, which is also more closely related to the drive cycle operation of PEMFC on vehicles [36], than during the constant potential or constant current testing. Borup et al. $[37,38]$ suggested that potential cycling is as a possible accelerated testing method for electrocatalysts.

\section{Conclusions}

The stability of both SWCNT- and MWCNT-supported Pt was investigated once during potential cycling from -0.3 to $1.2 \mathrm{~V}$ at $50 \mathrm{mV} \mathrm{s}^{-1}$ and once during the $0.9 \mathrm{~V}$ potentiostatic $24 \mathrm{~h}$ hold test using GDEs in an ADT cell at $60^{\circ} \mathrm{C}$. In the potential cycling, more quinine/hydroquinone redox couple was observed for both GDEs. GDE1 (with SWCNT as Pt support) was shown to be more stable than GDE2 to carbon corrosion (just in carbon corrosion, not in catalyst detachment). After potentiostat $24 \mathrm{~h}$ hold test at $0.9 \mathrm{~V}$, loss of EAS was observed for both GDEs. Even after the potentiostatic test, GDE2 showed higher EAS (thus better performance) and less EAS decrease than GDE1. It shows that the durability and stability of GDE2 is higher than GDE1.

The CVs showed increased EAS loss of the GDEs with the potential cycling. In contrary, more performance degradation of GDE1 (than GDE2) occurred due to the significant EAS loss of Pt/SWCNT cathode electrocatalyst, which resulted from the serious detachment of Pt particles from SWCNT support during potential cycling. These results clearly indicate that GDE2 is more durable than GDE1.

\section{References}

[1] D. Thompsett, W. Vielstich, A. Lamm, and H. A. Gasteiger, Handbook of Fuel Cells, Fundamentals Technology and Applications, John Wiley \& Sons, New York, NY, USA, 2003.

[2] E. Antolini, "Formation, microstructural characteristics and stability of carbon supported platinum catalysts for low temperature fuel cells," Journal of Materials Science, vol. 38, no. 14, pp. 2995-3005, 2003.

[3] J. Xie, D. L. Wood, K. L. More, P. Atanassov, and R. L. Borup, "Microstructural changes of membrane electrode assemblies during PEFC durability testing at high humidity conditions," Journal of the Electrochemical Society, vol. 152, no. 5, pp. A1011-A1020, 2005.

[4] X. Cheng, L. Chen, C. Peng, Z. Chen, Y. Zhang, and Q. Fan, "Catalyst microstructure examination of PEMFC membrane electrode assemblies versus time," Journal of the Electrochemical Society, vol. 151, no. 1, pp. A48-A52, 2004.

[5] Z. Siroma, K. Ishii, K. Yasuda, Y. Miyazaki, M. Inaba, and A. Tasaka, "Imaging of highly oriented pyrolytic graphite corrosion accelerated by Pt particles," Electrochemistry Communications, vol. 7, no. 11, pp. 1153-1156, 2005.

[6] L. Li and Y. Xing, "Electrochemical durability of carbon nanotubes in noncatalyzed and catalyzed oxidations," Journal of 
the Electrochemical Society, vol. 153, no. 10, pp. A1823-A1828, 2006.

[7] Y. Y. Shao, G. P. Yin, Y. Z. Gao, and P. F. Shi, "Durability study of PtC and PtCNTs catalysts under simulated PEM fuel cell conditions," Journal of the Electrochemical Society, vol. 153, no. 6, pp. A1093-A1097, 2006.

[8] H. Binder, A. Köhling, K. Richter, and G. Sandstede, "Über die anodische oxydation von aktivkohlen in wässrigen elektrolyten," Electrochimica Acta, vol. 9, no. 3, pp. 255-274, 1964.

[9] K. Kinoshita, Carbon Electrochemical and Physicochemical Properties, John Wiley \& Sons, New York, NY, USA, 1988.

[10] Y. Y. Shao, G. P. Yin, J. Zhang, and Y. Z. Gao, "Comparative investigation of the resistance to electrochemical oxidation of carbon black and carbon nanotubes in aqueous sulfuric acid solution," Electrochimica Acta, vol. 51, no. 26, pp. 5853-5857, 2006.

[11] R. Kou, Y. Shao, D. Wang et al., "Enhanced activity and stability of Pt catalysts on functionalized graphene sheets for electrocatalytic oxygen reduction," Electrochemistry Communications, vol. 11, no. 5, pp. 954-957, 2009.

[12] J. Lee, J. Kim, and T. Hyeon, "Recent progress in the synthesis of porous carbon materials," Advanced Materials, vol. 18, no. 16, pp. 2073-2094, 2006.

[13] R. Andrews, D. Jacques, D. Qian, and T. Rantell, "Multiwall carbon nanotubes: synthesis and application," Accounts of Chemical Research, vol. 35, no. 12, pp. 1008-1017, 2002.

[14] H. J. Dai, "Carbon nanotubes: synthesis, integration, and properties," Accounts of Chemical Research, vol. 35, no. 12, pp. 1035-1044, 2002.

[15] A. M. Kannan and L. Munukutla, "Carbon nano-chain and carbon nano-fibers based gas diffusion layers for proton exchange membrane fuel cells," Journal of Power Sources, vol. 167, no. 2, pp. 330-335, 2007.

[16] A. L. Dicks, “The role of carbon in fuel cells," Journal of Power Sources, vol. 156, no. 2, pp. 128-141, 2006.

[17] P. Serp, M. Corrias, and P. Kalck, "Carbon nanotubes and nanofibers in catalysis," Applied Catalysis A, vol. 235, no. 2, pp. 337-358, 2003.

[18] K. Lee, J. J. Zhang, H. J. Wang, and D. P. Wilkinson, "Progress in the synthesis of carbon nanotube- and nanofiber-supported Pt electrocatalysts for PEM fuel cell catalysis," Journal of Applied Electrochemistry, vol. 36, no. 5, pp. 507-522, 2006.

[19] C. A. Bessel, K. Laubernds, N. M. Rodriguez, and R. T. K. Baker, "Graphite nanofibers as an electrode for fuel cell applications," Journal of Physical Chemistry B, vol. 105, no. 6, pp. 1115-1118, 2001.

[20] X. Wang, W. Li, Z. Chen, M. Waje, and Y. S. Yan, "Durability investigation of carbon nanotube as catalyst support for proton exchange membrane fuel cell," Journal of Power Sources, vol. 158, no. 1, pp. 154-159, 2006.

[21] J. Wang, G. Yin, Y. Shao, S. Zhang, Z. Wang, and Y. Gao, "Effect of carbon black support corrosion on the durability of $\mathrm{Pt} / \mathrm{C}$ catalyst," Journal of Power Sources, vol. 171, no. 2, pp. 331-339, 2007.

[22] J. Wang, G. Yin, Y. Shao, Z. Wang, and Y. Gao, "Investigation of further improvement of platinum catalyst durability with highly graphitized carbon nanotubes support," Journal of Physical Chemistry C, vol. 112, no. 15, pp. 5784-5789, 2008.

[23] A. Kongkanand, S. Kuwabata, G. Girishkumar, and P. Kamat, "Single-wall carbon nanotubes supported platinum nanoparticles with improved electrocatalytic activity for oxygen reduction reaction," Langmuir, vol. 22, no. 5, pp. 2392-2396, 2006.
[24] H. R. Colón-Mercado and B. N. Popov, "Stability of platinum based alloy cathode catalysts in PEM fuel cells," Journal of Power Sources, vol. 155, no. 2, pp. 253-263, 2006.

[25] P. Yu, M. Pemberton, and P. Plasse, "PtCo/C cathode catalyst for improved durability in PEMFCs," Journal of Power Sources, vol. 144, no. 1, pp. 11-20, 2005.

[26] J. Perez, E. R. Gonzalez, and E. A. Ticianelli, "Oxygen electrocatalysis on thin porous coating rotating platinum electrodes," Electrochimica Acta, vol. 44, no. 8-9, pp. 1329-1339, 1998.

[27] Y. Xing, L. Li, C. C. Chusuei, and R. V. Hull, "Sonochemical oxidation of multiwalled carbon nanotubes," Langmuir, vol. 21, no. 9, pp. 4185-4190, 2005.

[28] A. N. Golikand, E. Lohrasbi, M. G. Maragheh, and M. Asgari, "Effect of carbon surface oxidation on platinum supported carbon particles on the performance of gas diffusion electrodes for the oxygen reduction reaction," Journal of Applied Electrochemistry, vol. 38, no. 6, pp. 869-874, 2008.

[29] M. Ciureanu and H. Wang, "Electrochemical impedance study of electrode-membrane assemblies in PEM fuel cells. I. Electrooxidation of $\mathrm{H}_{2}$ and $\mathrm{H}_{2} / \mathrm{CO}$ mixtures on Pt-based gas-diffusion electrodes," Journal of the Electrochemical Society, vol. 146, no. 11, pp. 4031-4040, 1999.

[30] P. J. Ferreira, G. J. La O', Y. Shao-Horn et al., "Instability of $\mathrm{Pt} / \mathrm{C}$ electrocatalysts in proton exchange membrane fuel cells: a mechanistic investigation," Journal of the Electrochemical Society, vol. 152, no. 11, pp. A2256-A2271, 2005.

[31] R. M. Darling and J. P. Meyers, "Kinetic model of platinum dissolution in PEMFCs," Journal of the Electrochemical Society, vol. 150, no. 11, pp. A1523-A1527, 2003.

[32] H. I. Elim, W. Jia, G. H. Ma, C. H. Sow, and C. H. A. Huan, "Ultrafast absorptive and refractive nonlinearities in multiwalled carbon nanotube films," Applied Physics Letters, vol. 85, no. 10, article 1799, 3 pages, 2004.

[33] J. S. Lauret, C. Voisin, G. Cassabois et al., "Ultrafast carrier dynamics in single-wall carbon nanotubes," Physical Review Letters, vol. 90, no. 5, Article ID 057404, 4 pages, 2003.

[34] K. H. Kangasniemi, D. A. Condit, and T. D. Jarvi, "Characterization of vulcan electrochemically oxidized under simulated PEM fuel cell conditions," Journal of the Electrochemical Society, vol. 151, no. 4, pp. E125-E132, 2004.

[35] J. S. Ye, X. Liu, H. F. Cui, W. D. Zhang, F. S. Sheu, and T. M. Lim, "Electrochemical oxidation of multi-walled carbon nanotubes and its application to electrochemical double layer capacitors," Electrochemistry Communications, vol. 7, no. 3, pp. 249-255, 2005.

[36] R. Makharia, S. Kocha, P. Yu, M. Sweikart, W. Gu, and F. Wagner, "Durable PEM fuel cell electrode materials: requirements and benchmarking methodologies," ECS Transactions, vol. 1, no. 8, pp. 3-18, 2006.

[37] R. Borup, J. Davey, D. Wood, F. Garzon, and M. Inbody, doehydrogen program fy, Progress report VII.I. 3, p.1039, 2005.

[38] R. L. Borup, J. R. Davey, F. H. Garzon, D. L. Wood, and M. A. Inbody, "PEM fuel cell electrocatalyst durability measurements," Journal of Power Sources, vol. 163, no. 1, pp. 76-81, 2006. 


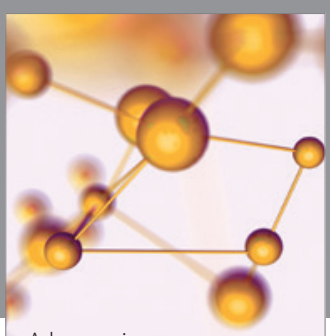

Physical Chemistry
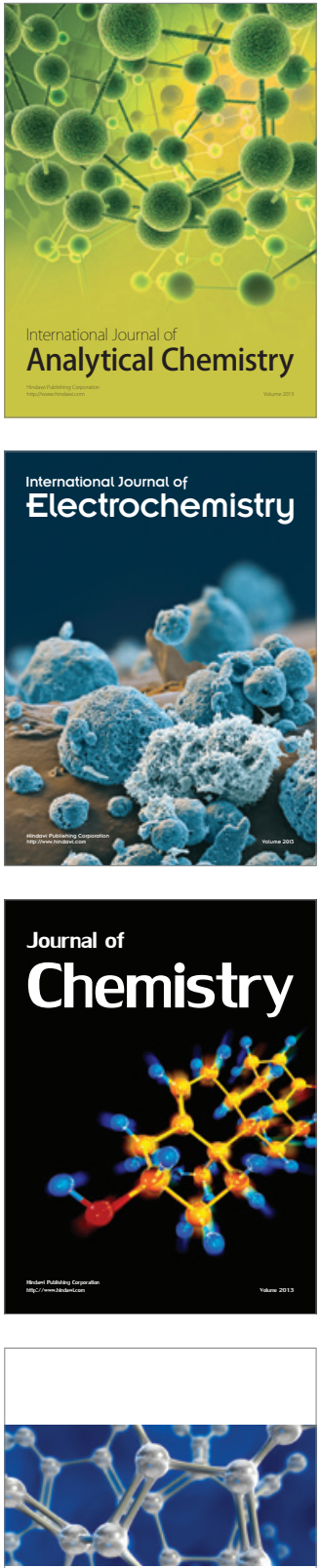

ISRN

Inorganic Chemistry

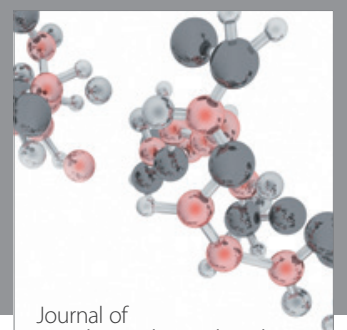

Analytical Methods in Chemistry

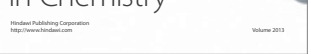

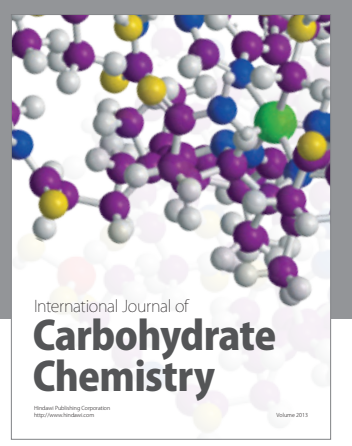
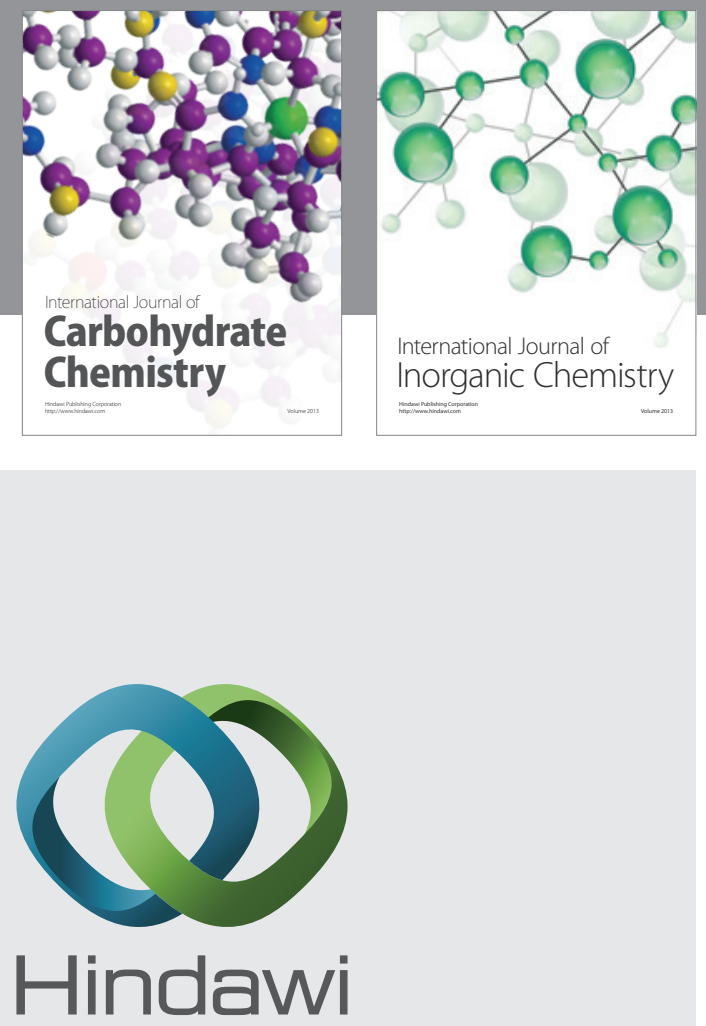

Submit your manuscripts at http://www.hindawi.com
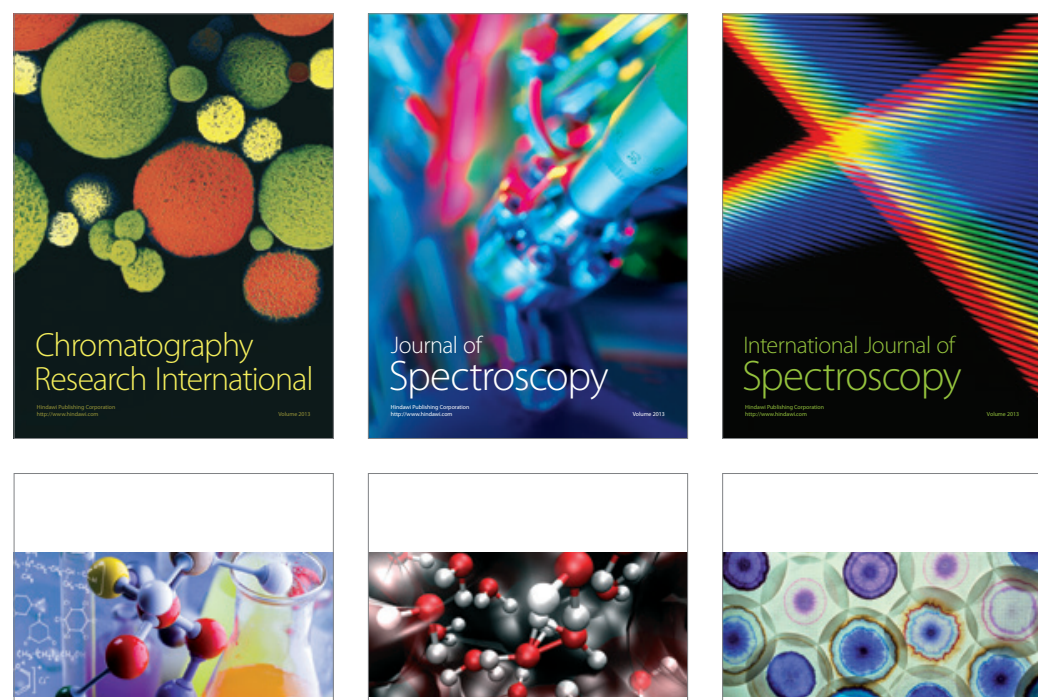

ISRN

ISRN

Organic Chemistry

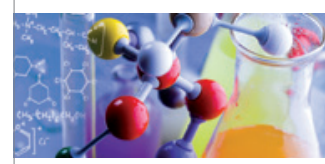

Physical Chemistry

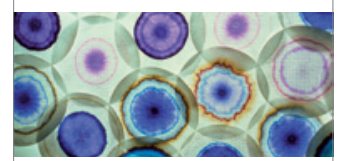

ISRN

Chromatography

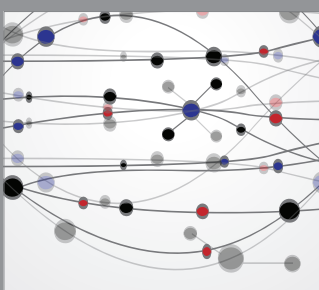

The Scientific World Journal
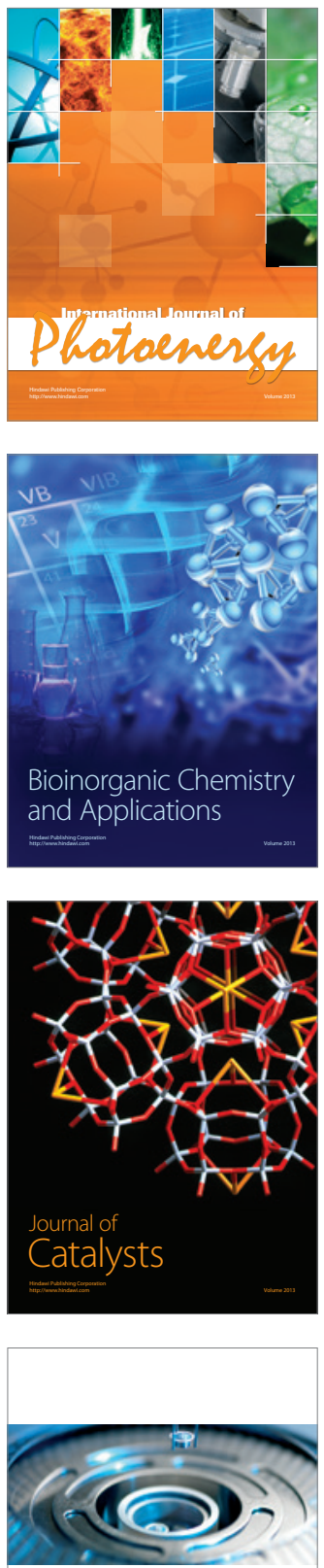

ISRN

Analytical

Chemistry 


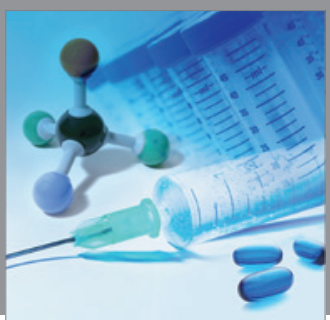

International Journal of

Medicinal Chemistry

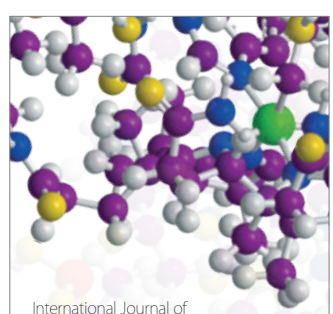

Carbohydrate Chemistry

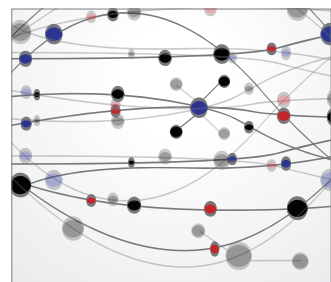

The Scientific World Journal
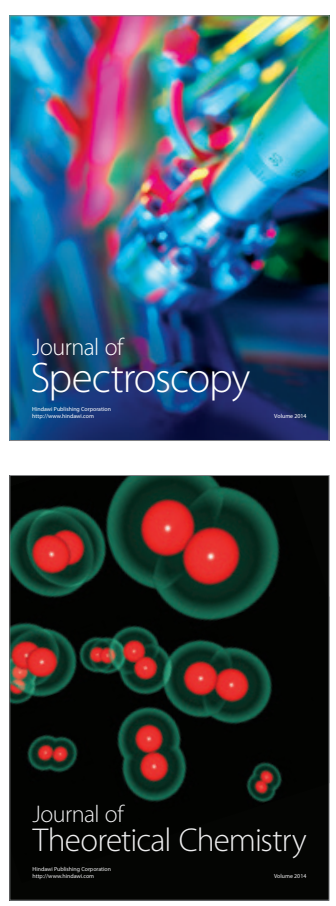
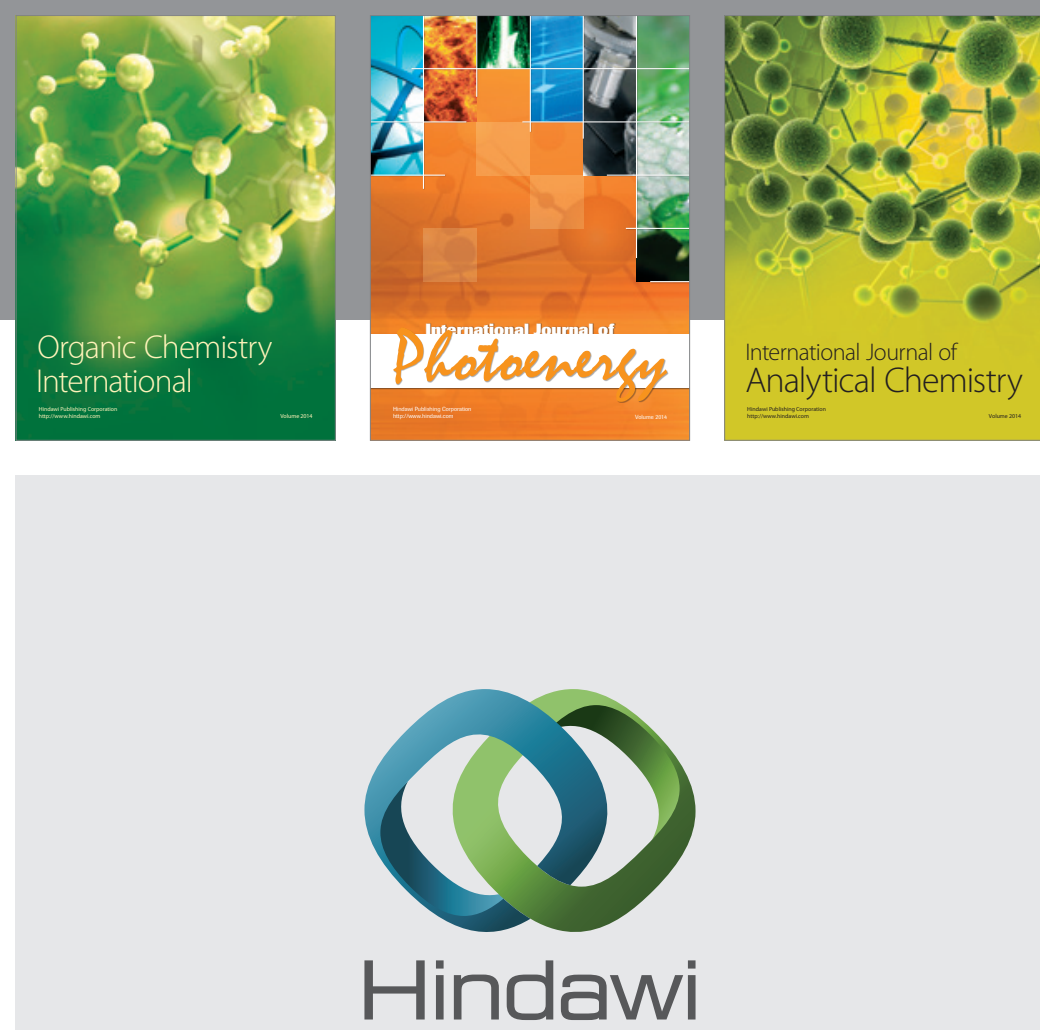

Submit your manuscripts at

http://www.hindawi.com
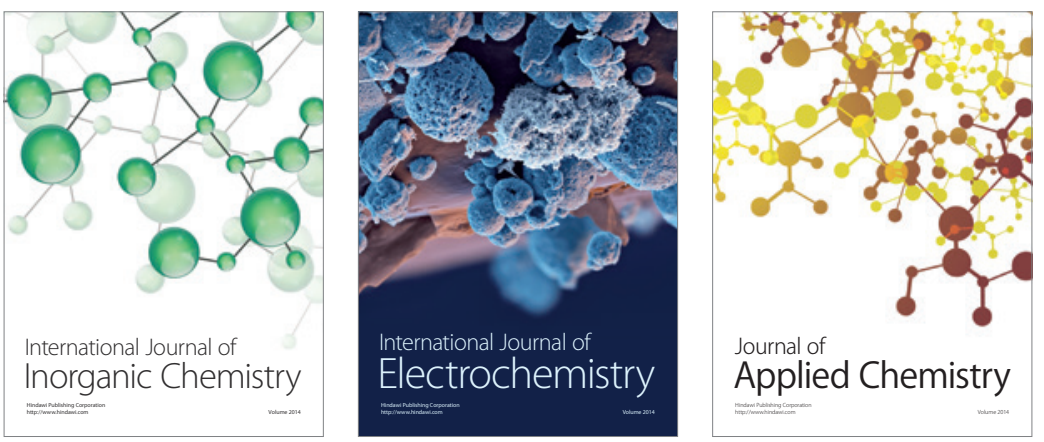

Journal of

Applied Chemistry
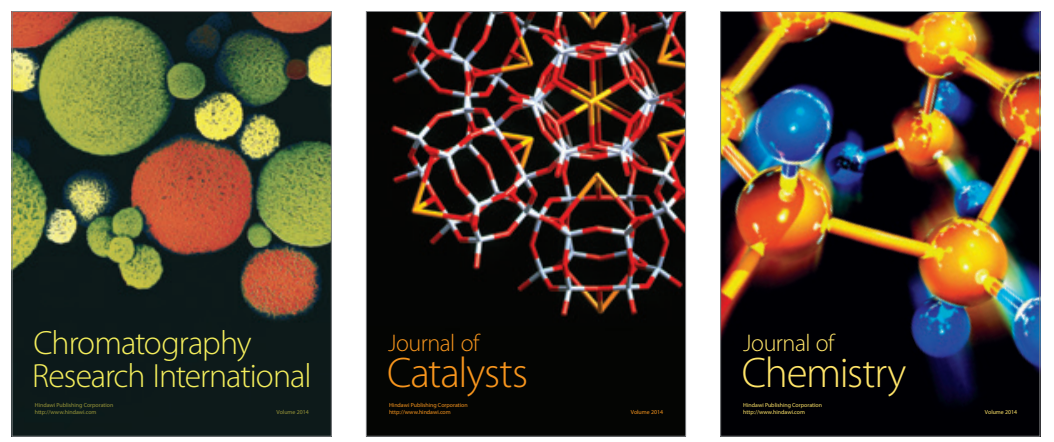
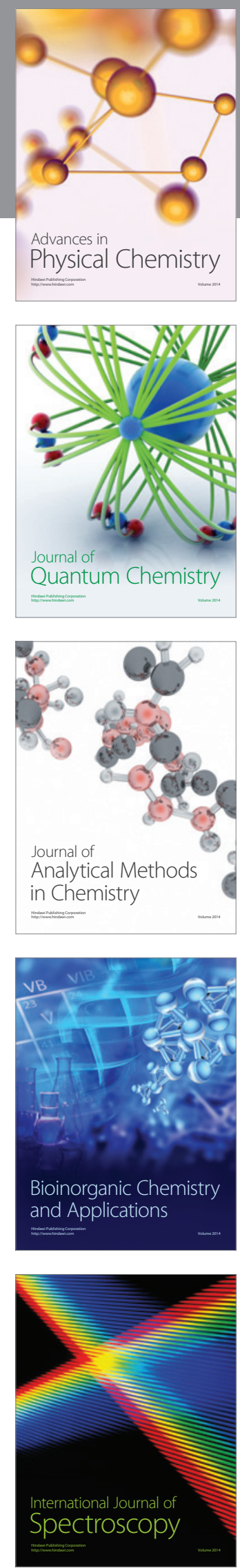